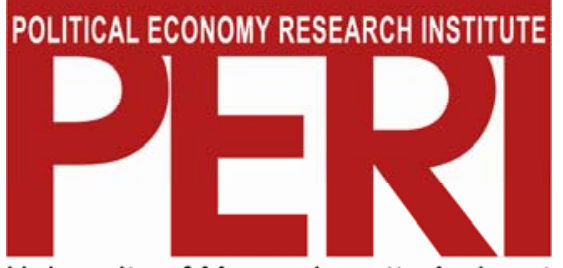

University of Massachusetts Amherst

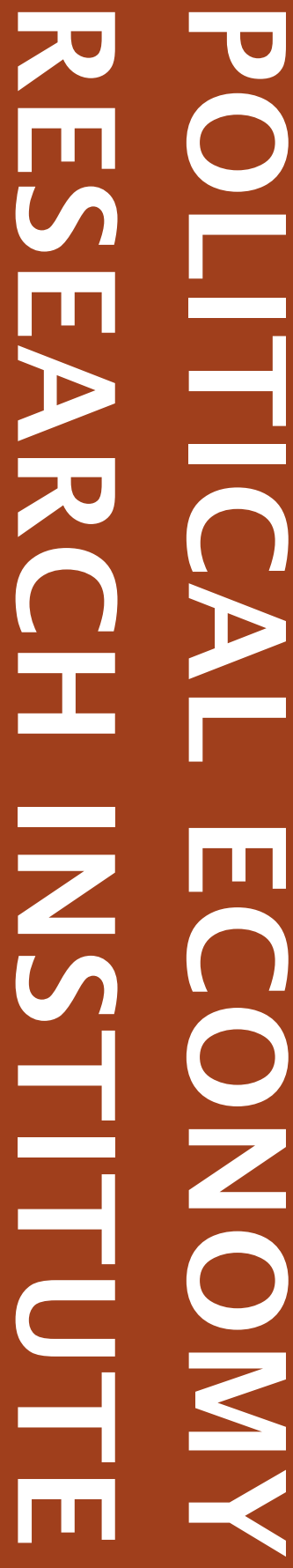

Engelbert Stockhammer \& Robert Stehrer

June 2009

Goodwin or Kalecki in Demand?

Functional Income Distribution and Aggregate Demand in the Short Run

Gordon Hall

418 North Pleasant Street

Amherst, MA 01002

Phone: 413.545 .6355

Fax: 413.577 .0261

peri@econs.umass.edu www.peri.umass.edu 


\title{
Goodwin or Kalecki in demand? Functional income distribution and aggregate demand in the short run
}

\author{
Version $1.0 \quad$ June $17^{\text {th }}, 2009$
}

\author{
Engelbert Stockhammer* and Robert Stehrer** \\ Contact: Engelbert.stockhammer@wu-wien.ac.at \\ * Vienna University of Economics and Business \\ ** Vienna Institute for International Economic Studies
}

\begin{abstract}
In a seminal paper on Marxian business cycle theory Goodwin (1967) presented a model, which assumed that a higher wage share leads to lower investment and thus a general economic slowdown. In contrast Kalecki (1971) was arguing that a higher wage share would have an expansionary effect because the consumption propensity out of wage income is higher than that out of profit income. Based on a general model that allows for wage-led as well as profit-led demand regimes, this paper estimates the effects of a change in the wage share on aggregate private domestic demand with quarterly data for 12 OECD countries.
\end{abstract}

JEL code: E11, E12, E20, E22, E25

Keywords: functional income distribution, demand, Goodwin cycle, Kalecki, Post Keynesian economics, Marxian economics

An earlier version of this paper has been presented at the Workshop Keynesian Economics and European Economic Policies, Berlin July 2008. The authors are grateful to the participants at the discussion there and to Peter Flaschel, Özlem Onaran, and Lance Taylor for comments. The usual disclaimers apply. 


\section{Goodwin or Kalecki in demand? Functional income distribution and aggregate demand in the short run}

\section{Introduction}

In a seminal paper Goodwin (1967) presented a model of a Marxian business cycle, where a higher wage share depresses investment expenditures. Sluggish investment translates into higher unemployment, which in turn decreases the wage share. This in turn stimulates investment and eventually employment. Thus the wage share rises again and the cycle is complete. Later on Goodwin $(1983,1986)$ noted that once unemployment and flexible capacity utilization is allowed for, an increase in the wage share need not lead to a decrease in demand. This is what Kalecki had already been arguing much earlier: a rise in the wage share would actually stimulate demand as the consumption propensity out of wage income is higher than that of profit income. Therefore a rise in the wage share will boost consumption expenditures.

This disagreement is cause as well as a symptom of a divide in heterodox macroeconomics. While Marxists (certainly those in the Goodwin tradition) accept as a stylized fact that an increase in profits will ceteris paribus stimulate growth, Post Keynesians routinely assert the opposite (at least for the closed economy case). Bhaduri and Marglin (1990) proposed a general Post Keynesian macro model that incorporates effects on demand as well as on investment which consequently can give rise to wage-led as well as profit-led demand regimes (see also Barbosa-Filho and Taylor, 2006). The profit-led demand regime can be considered the Goodwin case, the wage-led regime the Kaleckian case. However, associating these cases with the names of Goodwin and Kalecki respectively is admittedly somewhat arbitrary. While we will refer to the causal chain higher profit share $\rightarrow$ higher investment $\rightarrow$ higher aggregate demand (or growth) as the Goodwin-story, we might as well label it the 'Marx-story' or, indeed, the 'classical story'. In the light of the Bhaduri and 
Marglin model, the Goodwin story assumes that the effect of a change in income distribution on investment is stronger than that on consumption. Instead of Kalecki we might also refer to the Post Keynesian tradition in general when we refer to the causal chain higher wage share $\rightarrow$ higher consumption $\rightarrow$ higher aggregate demand. Implicit in Kalecki's argument is that the effect on consumption overpowers that on investment.

Two clarifications are necessary. First, the Goodwin-story and the Kaleckian story give sufficient conditions for demand to be profit led and wage led respectively. There could also be 'perverse' reasons for an economy to be profit led: if consumption reacted negatively to an increase in the wage (or if investment reacted positively to an increase in the wage share). Second, for any individual country there will also be an effect on net exports because given the level of productivity an increase in the wage share typically comes with an increase in prices, which implies a loss in international competitiveness (Blecker 1979, 1999, 2002). However, while empirically important, this international trade effect is not of further interest in our context, because there is no disagreement on it. The disagreement is on the domestic effects as both, the Goodwin and the Kalecki models are formulated in a closed economy setting. The disagreement between the two is about the relative size of the effects of a change in income distribution on consumption and on investment.

This paper contributes to the debates in heterodox macroeconomics on the empirical identification of distribution-led demand regimes. The question what the effects of a change in the wage share on private domestic demand is, will be investigated econometrically for 12 OECD countries. The estimation is based on model closely related to those of Bhaduri and Marglin (1990) and Barbosa-Filho and Tayor (2006). The contribution of this paper lies in using quarterly data for a broad set of countries and having an explicit focus on the short term and on the domestic economy. As we are using several countries a panel might seem appropriate. However since we are using quarterly data there will be experimentation with the 
lag structure and it would seem overly restrictive to impose the same temporal structure on all countries. Thus separate equations are estimated separately for each country.

While the Goodwin model is a model of the business cycle, this paper has a narrower focus: demand formation. Thus no complete test of the Goodwin model is intended. Rather one building block of the Goodwin model, that is, the demand side, is investigated.

Goodwin's as well as Kalecki's theory of income distribution is not subject of this paper.

The paper is structured as follows. Section 2 presents the theoretical background and the model, on which the empirical estimations are based. Section 3 summarizes the empirical literature on these models. Section 4 presents the econometric results for the effect of changes in functional income distribution on private consumption, and private investment. Section 5 summarizes the key findings and discusses theoretical implications and policy conclusions.

\section{Theoretical background: wage-led und profit-led demand regimes}

This section will present the macroeconomic model that forms the basis for the empirical analysis of the effects of changes in functional income distribution on aggregate demand. Aggregate demand (Y) is the sum of consumption (C), investment (I), net exports (NX) and government expenditure $(\mathrm{G})$ where all variables are expressed in real terms. In a general formulation, consumption, investment and net exports are written as functions of income (Y), the wage share $(\mathrm{W})$, and some other control variables (summarized as $\mathrm{z}$ ) which are independent of output and distribution. A full macroeconomic model would also include the effects of international trade. However, the international trade effect will not be investigated any further in this paper mainly because the difference of the arguments of Kalecki and 
Goodwin are not related to the respective treatment of international trade. ${ }^{1}$ The resulting model is of a basic private closed economy type and has several simplifications. Government expenditures can react to income distribution; however this is ignored in our analysis, which focuses on the private sector. Because of our focus on the effect of changes in functional income distribution on demand in the short run the effects of fiscal policy are excluded from the analysis. Income distribution, i.e. the wage share, ${ }^{2}$ is taken as predetermined. Aggregate private domestic demand $\left(\mathrm{Y}^{\mathrm{PD}}\right)$ can then be written as

$$
Y^{P D}=C\left(Y, W, z_{C}\right)+I\left(Y, W, z_{I}\right)
$$

In the consumption function the basic assertion is that wage incomes and profit incomes are associated with different propensities to consume. The Kaleckian assumption is that the marginal propensity to consume is lower for capital incomes than for wage income; consumption is therefore expected to increase when the wage share rises.

Investment depends positively on output (Y) and negatively on the wage share. In classical economics it was a straightforward assumption that the capital accumulation was a positive function of the rate of profit. Consequently investment ought to be a function of profits. Today it is often argued that retained earnings are a privileged source of finance and may thus influence investment expenditures.

Differentiating $\mathrm{Y}$ with respect to $\mathrm{W}$ and collecting terms gives

$$
\frac{d Y^{*}}{d W}=\frac{h_{2}}{1-h_{1}}
$$

\footnotetext{
${ }^{1}$ Net exports are a negative function of domestic demand, a positive function of foreign demand, and will depend negatively on unit labour costs, which are by definition closely related to the wage share, because they affect international competitiveness. (Blecker 1989, 2002; Stockhammer et al 2009)

${ }^{2}$ Functional income distribution and its measure, the wage share, are used synonymously throughout this paper.
} 
where $h_{1}=\left(\frac{\partial C}{\partial Y}+\frac{\partial I}{\partial Y}\right)$ and $h_{2}=\left(\frac{\partial C}{\partial W}+\frac{\partial I}{\partial W}\right)$.

The term $1 /\left(1-h_{1}\right)$ in equation (2) is a standard multiplier and has to be positive for stability. The sign of the total derivative therefore depends on the sign of the numerator. $\mathrm{h}_{2}$ is the sum of the partial derivatives of the components of demand with respect to income distribution. This sum is private excess demand, that is, the change in demand caused by a change in income distribution given a certain level of income. It is impossible to sign $\mathrm{h}_{2}$ a priori, since we hypothesize that $\partial \mathrm{C} / \partial \mathrm{W}>0$ and $\partial \mathrm{I} / \partial \mathrm{W}<0$. The sum of these effects can therefore only be determined empirically. Determining the sign of private domestic excess demand is the focus of the empirical estimations in this study.

The total effect of the increase in the wage share depends on the relative size of the reactions of the components of GDP, namely consumption and to changes in income distribution. If it is positive $(\partial \mathrm{Y} * / \partial \mathrm{W}>0)$, the demand regime is called wage-led. If the effect is negative $\left(\partial \mathrm{Y}^{*} / \partial \mathrm{W}<0\right)$, it is called profit-led. If consumption reacts more sensitive to an increase in the wage share than investment, domestic demand will be wage-led.

To close the model a theory of income distribution is required. The wage share is a function of demand and some exogenous factors, i.e. $W=W\left(Y, z_{W}\right)$. A Goodwinian distribution function implies that the wage share is an increasing function of economic activity as output growth typically comes with employment growth and a depletion of the industrial reserve army (unemployment). On the other hand, from a Kaleckian perspective the profit share will vary pro-cyclically because there are overhead costs (and overhead labour) and the mark up is relatively stable. Thus, complementary to the disagreement on the demand side, there is also a disagreement on the theory of distribution. This paper, however, only deals with the disagreement on the demand side. 


\section{Related empirical literature}

The debate in the Goodwinian (Marxian) tradition and the Post Keynesian debates have proceeded along independent lines without much interaction. One reason for this lack of interaction is that the research questions have been framed in different ways. The Goodwin business cycle theory aims at analyzing a system of (usually two) equations, but much less (if any) effort is spent on the identification of behavioural demand equations such as the investment function. Kaleckians are interested in the nature of the demand regime and (mostly) do not put forward a full theory of the business cycle. The Kaleckians offer sophisticated (or at least disaggregated) analysis of demand, but the determination of income distribution is hardly ever investigated empirically in this context.

There is a long-standing debate in Marxian economics on the nature of crises and the cause of crises, usually summarized as relating to either the realization/underconsumption (due to a lack of demand), profit squeeze (due to increasing strength of labour) and organic composition of capital. The profit squeeze tradition predates Goodwin, but he has since become an important reference point in the debate. Goldstein (1999) estimates a two equation VAR with unemployment and the profit share, but the results cannot be interpreted as a demand functions. Harvie (2000) follows Goodwin in assuming that all profits get automatically reinvested. Consequently there is no demand side to be estimated, but only various components of the distribution side. Mohun and Venziano's (2007) contribution lies in the careful discussion of the definition of profits and wages. They aim to identify the cycle and its forces by providing a discussion of plots of HP-filtered data, but no econometric analysis of the relevant behavioural equations is undertaken.

Barbosa-Filho and Taylor (2006) is closest among the Goodwin-inspired literature to our approach. They estimate a two equation VAR with a demand equation and a distribution equation (without contemporaneous interaction) for the US economy using quarterly data and the cyclical component of the HP filter. The effects for individual components of demand are 
then decomposed from the aggregate results (rather than estimated as behavioural equations). This gives strong perverse results in the consumption function. The (negative) effect of an increase in the wage share on consumption is larger than those on investment and net exports combined. They conclude that the US economy is in a profit-led demand regime.

As Barbosa-Filho and Taylor (2006) is closely related to our work, we have tried to replicate their results, which revealed several severe limitations of their approach. First, Barbosa-Filho and Taylor use the cyclical component of an HP filter. The regression results with these variables suffer from severe autocorrelation problems and are therefore biased. Second, the results are very sensitive to the lag length included. While a lag length of two gives the profit-led regime found by Barbosa-Filho and Taylor, a lag length of four gives wage-led results. Overall, their results suffer from several econometric problems and are not robust.

Research in the Kaleckian tradition has recently produced a number of contributions on the identification of the demand regime. The starting point for this literature is the Bhaduri and Marglin (1990) model, which is a flexible Post-Kaleckian macro model that allows for wage-led as well as profit-led demand regimes. The tests of the Bharduri-Marglin models can be grouped into two estimation strategies. The first group of papers tries to estimate the full model, that is, a goods market equilibrium relation and a distribution function. Stockhammer and Onaran (2004) estimate a structural VAR model consisting of the variables capital accumulation, capacity utilization, profit share, unemployment rate and labor productivity growth for the USA, UK and France. The goods market is estimated by a model based on Marglin and Bhaduri (1990). From the empirical investigation it is concluded that unemployment is determined by the goods market, and that the impact of income distribution on demand and employment is very weak. Onaran and Stockhammer (2005) employ a similar model for Turkey and Korea and find some indication for wage-led demand regimes in these countries. The advantage of the systems approach is that the interaction between the variables 
can be incorporated. The disadvantage of the VAR is that it is difficult to identify effects of individual variables.

Flaschel and Proano (2007) investigate the effects of the Taylor rule in a macroeconomic model that highlights disequilibrium dynamics. The focus of the paper thus is not on the distribution-led demand regime. However, empirically, they estimate a five equation model (for wages, prices, capacity utilization, unemployment and the interest rate) for the Euro area and Germany and find that both have a profit-led demand regime. They use a GMM estimator to address simultaneity and do not include lagged effects. No disaggregate effects for investment and consumption are identified.

The second, larger group of papers analyses the goods market in isolation. Typically behavioral functions are estimated for consumption, investment and net exports. The first paper along these lines was Bowles and Boyer (1995). Naastepad and Storm (2006/2007) for eight and Hein and Vogel (2008a) for six OECD countries are more recent examples. All of them use annual data and look at long run effects. Stockhammer et al (2009) for the Euro area offer a more sophisticated treatment of international trade by estimating separate price equations and, import and export equations. This allows to trace the effects of changes in distribution through prices to exports and imports. Stockhammer et al (2010) develop this further and analyze the effects of globalization on the link between income distribution and demand for Germany.

The empirical evidence generated by this literature on the nature of domestic demand regimes is overwhelmingly in support of wage led (domestic) demand regimes. Bowles and Boyer (1995) and Hein and Vogel (2008) find wage-led domestic demand regimes in all countries including Germany, France, UK and USA. Only Storm and Naastepad (2006/07) find profit-led demand regimes in the USA and Japan, but wage-led demand regimes in other countries. Stockhammer et al (2009), Ederer and Stockhammer (2007), Stockhammer and 
Ederer (2008) and Stockhammer et al. (2010) find wage-led domestic demand regimes in the Euro area, France, Austria, and Germany respectively.

This paper is more closely related to the Post Kaleckian approach as the emphasis is on the estimation of behavioral equations for private consumption and investment. It does not explicitly advance a theory of the business cycle. Its contribution lies in the analysis of twelve countries using quarterly data and an explicit focus on short run effects. The econometric specifications resemble those of Barbosa-Filho and Taylor (2006), but a different estimation strategy is applied. Rather than estimating a system of demand and unemployment equations, and thereafter decomposing demand, we estimate the individual behavioral functions that constitute private domestic demand. Moreover we use difference and ECM specifications instead of cyclical components of the HP-filter, because the latter come with serious autocorrelation problems. We also pay substantially more attention to the lag structure compared to Barbosa-Filho and Taylor (2006).

\section{Empirical results}

As we are interested in the short-run effects of distribution on demand difference specifications will be applied. ECM specifications were not applicable, because of lack of evidence of cointegration. One important question is how to deal with the contemporaneous interactions between demand and distribution. Including contemporaneous effects will lead to endogeneity problems. Moreover, Granger causality tests strongly suggest that the causality goes from consumption and investment to income distribution rather than the other direction. ${ }^{3}$ While Granger causality test cannot resolve the question of causality in an economic sense, they certainly deliver a strong warning against including contemporaneous effects. To avoid simultaneity problems only predetermined, that is lagged, variables will be included. With

\footnotetext{
${ }^{3}$ For investment and the wage share we find support for the Granger-causality (with 4 lags) $\mathrm{I} \rightarrow \mathrm{W}$ in 6 countries and $\mathrm{W} \rightarrow \mathrm{I}$ in three countries; for consumption we find $\mathrm{C} \rightarrow \mathrm{W}$ in 10 countries and $\mathrm{W} \rightarrow \mathrm{C}$ in three countries.
} 
quarterly data the bias due to omitted contemporaneous effects should be minor. Incorporating contemporaneous effects is a major challenge as it cannot be done on purely empirical grounds; thus some theoretical restrictions would have to be applied. Any such approach would have to rely on instruments and results would thus critically depend on the quality of these instruments. The following two baseline specifications will be used:

$$
\begin{aligned}
& \Delta c_{t}=a_{0}+\sum_{k=1}^{K} a_{Y, k} \Delta y_{t-k}+\sum_{k=1}^{K} a_{W, k} \Delta w_{t-k}+\varepsilon_{t} \\
& \Delta i_{t}=b_{0}+\sum_{k=1}^{K} b_{Y, k} \Delta y_{t-k}+\sum_{k=1}^{K} b_{W, k} \Delta w_{t-k}+\varepsilon_{t}
\end{aligned}
$$

where $c, i, y$, and $w$ are the logarithms of (private) real consumption, (private) real investment, real GDP and the wage share respectively; $\mathrm{K}$ denotes the number of lags included. In a variation we also use an error correction specification that allows for long -run effects:

$$
\begin{aligned}
& \Delta c_{t}=a_{0}+\sum_{k=1}^{K} a_{Y, k} \Delta y_{t-k}+\sum_{k=1}^{K} a_{W, k} \Delta w_{t-k}+a_{E C}\left(c_{t-1}-a y_{t-1}\right)+\varepsilon_{t} \\
& \Delta i_{t}=b_{0}+\sum_{k=1}^{K} b_{Y, k} \Delta y_{t-k}+\sum_{k=1}^{K} b_{W, k} \Delta w_{t-k}+b_{E C}\left(i_{t-1}-b y_{t-1}\right)+\varepsilon_{t}
\end{aligned}
$$

The total effect on private excess demand, for convenience of interpretation expressed in percent of GDP, is the sum of the effects on consumption weighted by the consumption share in GDP and the inverse of the wage share plus the sum of the effects on investment weighted by investment share in GDP and the inverse of the wage share:

$$
\frac{\partial Y^{P D} / Y}{\partial W}=\sum_{k=1}^{K} a_{W, k} * \frac{C}{W . Y}+\sum_{k=1}^{K} b_{W, k} * \frac{I}{W . Y}
$$


where $\frac{C}{Y}, \frac{I}{Y}, \frac{1}{W}$ and denote averages over the total period. Data are collected from the OECD Economic Outlook database. All variables are seasonally adjusted quarterly data and cover the period 1970:1 to 2007:2. Data are available for twelve countries: Australia, Canada, Germany, Finland, France, United Kingdom, Ireland, Japan, Luxembourg, Netherlands, Sweden, and the United States. Data for Germany have been chained with data for West Germany prior to 1991.

In the econometric specifications the identification of the lag length is an important and delicate issue. Investigating the robustness of the results with respect to the specification and the lag length are a central concern of this paper. The presentation of the results will first present detailed results for a lag length of 4 . Second, summary results for lag lengths 2, 4, 6 and 8 will also be reported. For clarity of exposition we however report the summed coefficients only. ${ }^{4}$ Second, as these summed coefficients will contain many statistically insignificant coefficient estimates, we also report results for only those coefficients that have a t-value of higher than $1.8 .^{5}$ Third, an ECM version will be estimated and finally results of a differences specification applying a testing-down procedure will be reported.

\subsection{Baseline results}

Table 1 summarizes the results for the consumption function (3a) at a lag length of 4 . Overall the explanatory power of the estimated equations is moderate. Qualitatively, the results confirm to the expectation that an increase in the wage share increases consumption expenditures. In 8 of the 12 countries we find a statically significant effect (at the $5 \%$ level) of income on consumption, all with the expected sign. In 6 (Australia, Germany, Finland,

\footnotetext{
${ }^{4}$ Detailed results are available from the authors upon request.

${ }^{5}$ Using a t-value of 1.8 (i.e. roughly a significance level of $5 \%$ ) as cut off is arbitrary. Results are qualitatively very similar if a cut off of 2 is used.
} 
Luxembourg, Netherlands, and Sweden) of the 12 countries we find statistically significant effects of the wage share on consumption with the expected sign. A statistically significant perverse effect appears only for the UK. The large number of regressors may erode statistical significance due to multicollinearity. Therefore the last rows add up the sum of the coefficient estimates for the effects of income and the wage share.

\section{$<$ Insert Table 1 $>$}

The results for the consumption function at different lag lengths are summarized in Table 2.1. Here only the sum of the coefficients of the wage share is reported, as this is the variable of interest. Of course, in all specifications we do control for income (at the same number of lags) as indicated in equation (3a). Column "4lags" in Table 2.1 corresponds to the last row of Table 1. Overall the results are similar for different lag lengths. Ten of the 12 countries have positive signs on the coefficients on the wage share. Two countries have almost consistently perverse signs: the UK and Ireland. Australia and the United States have perverse signs once (with 6 lags) and twice (with 2 and with 6 lags) respectively. The choice of the lag length generally has little effect on the overall effect for the consumption function. For most countries the total effect is rather stable. For Germany and Sweden the effect seems to decline as the lag length increases, whereas for France and Luxembourg it seems to increase. Germany, France and Japan show relatively strong effects of income distribution on consumption expenditures. The mean effect of a change (in the log) of the wage share on (the change in the log of) consumption is 0.134 (at 6 lags) and 0.173 (at 4 lags).

$<$ Insert Table 2.1 $>$

$<$ Insert Table 2.2> 
Table 2.2 presents coefficients with a t-value of more than 1.8 . The results are broadly consistent with those already reported in Table 2.1 above. For Germany, Finland, France, Luxembourg, the Netherlands, and Sweden we find the expected positive effect on consumption. However, for Canada, Ireland, Japan, and the United States we never find statistically significant effects. The perverse effects in the UK (and Australia at lag lengths of 6 and 8) also show up if only statistically significant coefficients are taken into account. The mean effects are ranging from 0.075 (with 6 lags) to 0.096 (with 8 lags) and thus are somewhat lower than in the case with all coefficients.

These results support the hypothesis of a savings differential between capital and labour incomes in most countries even though the effects are of moderate size. It is intriguing to note that the only countries for which this relationship does not hold (or even shows perverse signs) are Anglo-Saxon countries (United Kingdom, Ireland, and the United States). But as one can see in Table 2.2 these perverse effects are often not statistically significant.

Table 3 reports the results of the investment function (equation 1b) at a lag length of 4 . Again we find strong evidence for the expected role of income. In 9 (out of 12) countries the effect is positive and statistically significant (at the 5\% level). In three cases (Ireland, Luxembourg and the Netherlands) we do note (statistically significant) perverse effects, but only in one case (the Netherlands) without an offsetting positive effect. The results for the effect of the wage share are much weaker. Only in three countries we do find a statistically significant negative effect of the wage share on investment.

\section{$<$ Insert Table 3>}

Tables 4.1 and 4.2 summarize the effects of a change in the wage share on investment at different lag lengths. Results for the investment equation are more sensitive to the lag length utilized than for the consumption function. For the majority of countries the effects are 
perverse at a lag length of two: increases in the wage share have a positive effect on investment. Only at higher lag lengths does the effect turn negative as expected. Investment seems to take time to react to changes in income distribution (though it is much quicker to react to changes in demand as can be seen from Table 3). In almost all countries the effect is larger at six lags than at 4 lags, whereas at lag length of 8 the results are less clear with several countries switching sign again. Effects are relatively strong in Australia, Canada, Germany, and France. ${ }^{6}$

$<$ Insert Table 4.1 $>$

$<$ Insert Table 4.2>

Table 4.2 summarizes the effects when considering only statistically significant variables (again defined as t-value of higher than 1.8), which confirms the mixed results above. Typically 8 of the 12 countries show no statistically significant effects. And typically we find two perverse cases: Ireland consistently shows negative effects (except at lag length 2) and Luxembourg has negative effects at lag lengths 4 and 6.

Overall we fail to find clear evidence that the increases in the wage share have a negative effect on investment. Results are sensitive to the lag length and mostly not statistically significant. Overall the results in Table 4.1 are suggestive of some, though elusive, effects. A potential explanation would be that investment is mainly determined by (expected) demand as emphasized in Keynesian models.

Total effects are reported in Table 5. These effects have been standardized as percent of GDP to facilitate interpretation. Again, Table 5.1 reports the results for all coefficients while Table 5.2 reports the effects for statistically significant effects. While the results are somewhat sensitive to the lag length, most countries show rather consistent signs. According

\footnotetext{
6 'Strong' means a coefficient estimate of larger than -.5 in at least two specifications.
} 
to these results, seven countries (Germany, Finland, France, Japan, Luxembourg, Netherlands and Sweden) show wage-led demand regimes in at least three of four specifications. Four countries show profit-led demand regimes in at least three of four specifications: Australia, UK, Ireland and the USA.

\author{
$<$ Insert Table 5.1 $>$ \\ $<$ Insert Table 5.2>
}

Not all these results are statistically significant. Table 5.2 reports the results for statistically significant coefficients only. Germany, Finland, France, Luxembourg, Netherlands and Sweden show wage-led demand regimes rather consistently, that is in at least three specifications, but only the UK shows a consistent profit-led demand regime. Australia is mixed, being wage-led up to four lags and profit-led thereafter; Ireland is now profit-led only with 2 lags, but wage-led at higher lag lengths and for the US (and Japan) no statistically significant effect is found.

\title{
4.2 Robustness checks
}

As robustness check we also estimated a restricted ECM specification (see equations (4a) and (4b) above). The unrestricted estimations failed to support a cointegrating relation with few exceptions and often gave perverse or implausible effects in the long-run relations. Thus a simple restriction was imposed on the long-run relation: the GDP-elasticity of consumption and of investment were restricted to unity and income distribution was excluded from the long run relation. This restriction has the advantage of being simple and, at least in its first part, theoretically plausible. As the consumption share and the investment share are stable (rather then trended over time), the respective elasticities have to be equal to one. As the interest here 
is not in modelling the long run relation itself, but rather on the robustness of the short-run results if long-run effects are allowed for, this simple version will suffice for the task at hand.

Tables 6.1 and 6.2 report the results, again for all and for the statistically significant coefficients only. The results broadly confirm the difference specifications. The results previously reported are thus robust to the inclusion of long-term effects. Again the continental European countries show relatively consistent (and statistically significant) wage-led domestic demand regimes, whereas the UK and Australia show consistent and statistically significant profit-led domestic demand regimes. The results for the US are again mixed and not statically significant. The results for Ireland are mixed as well.

\footnotetext{
$<$ Insert Table 6.1 $>$

$<$ Insert Table 6.2>
}

Finally, a difference specification (with 8 lags) was estimated using a testing down procedure by stepwise elimination of the coefficient with the lowest p-value until only coefficients statistically significant at the $10 \%$ level (given the standard critical t-value) remain. Such procedures are commonly used in time series econometrics, despite dubious statistical properties. Because of the repeated estimations the standard critical values do not apply. Moreover, in the course of the elimination procedure, individual coefficients repeatedly changed signs. The results are thus regarded as unreliable and are presented as a robustness check only. We find wage-led demand regimes for seven countries and profit-led regimes for five countries. Again the profit-led countries are mostly Anglo Saxon countries.

\subsection{Interpretation}

Given these results it is tempting to conclude that there is a group of continental European countries (maybe together with Japan) with wage-led domestic demand regimes and a second 
group of Anglo-Saxon countries prone to profit-led domestic demand regimes (though these findings often rely on statistically insignificant coefficients). ${ }^{7}$ From this Kalecki might seem more appropriate in Continental Europe and Goodwin in the Anglo-Saxon world. However, such an interpretation would be misleading: Both, scholars in the Kaleckian and in the Goodwin tradition agree on the partial effects: an increase in the wage share should stimulate consumption and depress investment. The disagreement is in the relative size of these effects and, consequently on the overall effect.

Note, however, that many of the profit-led economies are profit led for the 'wrong reason'. According to the Goodwin story countries should have profit-led demand regimes, because the effect of a change in the wage share on investment is stronger than that on consumption. However, the most consistently profit-led economy according to our findings, the UK, has a perverse effect in the consumption function, but no particularly strong (or statistically significant) investment effect. Ireland also has perverse (though not statistically significant) consumption effects and perverse investment effects in many specifications. For the US also about half of the results for investment and consumption are perverse, with none of the effects being statistically significant at all. In other words, the profit-led economies are not profit led for the reasons implied in Goodwin's theory of the business cycle. On the other hand, those countries for which the results for investment and consumption are well behaved (Germany, France, Netherlands and Sweden) almost consistently show wage-led demand regimes. The wage-led European economies are thus in line with the Kaleckian argument.

\footnotetext{
${ }^{7}$ It may be tempting to associate the Anglo-Saxon liberal market economies with a profit-led demand regime and the European welfare states with a wage-led regime. An analysis of the effects of different welfare regimes and financial systems does not support such an expectation. As welfare states come with a more egalitarian income distribution, one would expect the savings differential to be lower in Europe than in the Anglo-Saxon economies. Differences in the financial systems will have complex effects. In a bank-based system the credit lines of firms may be less dependent on recent profits (because of trust-based relations) than in market-based financial systems (where contracts are predominantly short term). This might be a reason for investment to be more profit-sensitive in Anglo-Saxon countries. However, if (as it is sometimes argued) market-based financial systems are more supportive of innovation, one might expect investment to depend less on recent profits.
} 
Rather than a Kaleckian group of wage-led European countries and a Goodwinian group of profit-led Anglo-Saxon countries, we find a well-behaved group of wage-led (and thus Kaleckian) European countries and a second group of countries (which are predominantely Anglo-Saxon) with perverse distribution effects in consumption. The burning question for the types of Post-Keynesian models estimated here, is thus why some predominantely Anglo-Saxon - countries show a perverse consumption differential. Neither Kalecki nor Goodwin offers much of an explanation here. One potential explanation would be missing variables. If asset prices were correlated with profits (a reasonable assumption) and the wealth effect in consumption were stronger in the Anglo-Saxon countries (for which there is some evidence), than the observed pattern might be the outcome. ${ }^{8}$

\section{Conclusion. One cheer for Kalecki}

Overall our results are more in line with Kalecki's theory. The savings differential is observable in most countries and is statistically significant. The investment effects of the wage share are often not statistically significant and they are usually sensitive to the specification. The Kaleckian story can explain the wage-led demand regimes for those countries where we find it. On the other hand we find little support for the Goodwin story of the demand side. Those countries for which we find profit-led demand regimes rely strongly on the role of profits on consumption rather than on investment. The link between profits and investment does not seem to be strong and reliable enough to carry the weight of the Goodwin story of the business cycle. One should however note that Goodwin (1967) is a model of the business cycle whereas our analysis is not one of the business cycle as such, but focuses on one of the component of a business cycle model only: the demand function, which has a key

\footnotetext{
${ }^{8}$ Onaran et al (2009) estimate and extend Bhaduri-Marglin model that include variables for housing wealth of households and dividend and interest payout of firms for the USA.
} 
role in the understanding of the business cycle. This paper has excluded the distribution function, which is subject to related disagreements between Marxists and Kaleckians. This would be an interesting topic for future research.

\section{References}

Barbosa-Filho, Nelson, Taylor, Lance (2006). Distributive and demand cycles in the US economy - a structuralist Goodwin model. Metroeconomica 57, 3, 389-411

Bhaduri, A., Marglin, S., 1990. Unemployment and the real wage: the economic basis for contesting political ideologies. Cambridge Journal of Economics, 14: 375-93

Blecker, R., 1989. International competition, income distribution and economic growth. Cambridge Journal of Economics, 13: 395-412

Blecker, R., 1999. Kaleckian macromodels for open economies, in Deprez, J. and Harvey, J.T (eds): Foundations of international economics: post Keynesian perspectives. Routledge, London, New York.

Bowles, S., Boyer, R., 1995. Wages, aggregate demand, and employment in an open economy: an empirical investigation, in: G Epstein and H Gintis (eds): Macroeconomic policy after the conservative era. Studies in investment, saving and finance. Cambridge University Press, Cambridge/UK.

Desai, M. (1973): 'Growth cycles and inflation in a model of class struggle', Journal of Economic Theory, 6, pp. 527-45.

Ederer, S. and Stockhammer, E. 2007. Wages and aggregate demand in France: An empirical investigation. Hein, E, Truger, A (eds): Money, distribution, and economic policy - alternatives to orthodox macroeconomics. Cheltenham: Edward Elgar

Goldstein, J. P. (1996): 'The empirical relevance of the cyclical profit squeeze: a reassertion', Review of Radical Political Economics, 28 (4), pp. 55-92.

Goldstein, J. P. (1999): 'The simple analytics and empirics of the cyclical profit squeeze and cyclical underconsumption theories: clearing the air', Review of Radical Political Economics, 31 (2), pp. 74-88.

Goldstein, J. P. 1999. Predator-Prey Model Estimates of the Cyclical Profit Squeeze. Metroeconomica 50, 2, , pp. 139-173

Goldstein, J.P., 1986. Markup Variability and Flexibility: Theory and Empirical Evidence. The Journal of Business, Vol. 59, No. 4, Part 1. (Oct., 1986), pp. 599-621.

Goodwin, R.M. (1967) "A Growth Cycle", in C.H. Feinstein, editor, Socialism, Capitalism and Economic Growth. Cambridge: Cambridge University Press.

Hein, E, Vogel, L, 2008. Distribution and growth reconsidered - empirical results for six OECD countries, Cambridge Journal of Economics, 32: 479-511.

Kalecki, M. 1954. Theory of Economic Dynamics. Reprinted in J. Osiatynski (ed): Collected Works of Michal Kalecki, Vol. 1, Oxford, Clarendon Press.

Marglin, S, Bhaduri, A, 1990. Profit Squeeze and Keynesian Theory, in: S. Marglin, Schor, J. (eds): The Golden Age of Capitalism. Reinterpreting the Postwar Experience. Oxford, Clarendon Press.

Marx, Karl, 1976. Capital. A Critique of Political Economy Volume One. London: Penguin Books

Naastepad, C.W.M., Storm, S, 2006/7. OECD demand regimes (1960-2000). Journal of Post-Keynesian Economics, 29: 213-248. 
Onaran, Ö, Stockhammer, E. 2005. Two different export-oriented growth strategies: accumulation and distribution a la Turca and a la South Korea. Emerging Markets Finance and Trade 41 (1), 65-89

Onaran, Ö, Stockhammer, E, Grafl, L, 2009. The finance-dominated growth regime, distribution, and aggregate demand in the US. Vienna University of Economics \& B.A. Dept. of Economics Working Paper No. 126

Flaschel P., Groh, G. 1995. The classical growth cycle: reformulation, simulation and some facts, Economic Notes 24 (1995), pp. 293-326.

Flaschel, P, Proano, C, 2007. AS-AD Disequilibrium dynamics and the Taylor interest rate policy rule: Euro-Area based estimation and simulation. In: P. Arestis, E. Hein and E. Le Heron (eds): Aspects of Modern Monetary and Macroeconomic Polices. Houndsmill: Palgrave MacMillan

Rowthorn, Robert, 1977. Conflict, inflation and money. Cambridge Journal of Economics 1, 3. Reprinted in: Bob Rowthorn: Capitalism, Conflict and Inflation. London: Lawrence and Wishart, 1980

Stockhammer, E, Onaran, Ö, Ederer, S. 2009. Functional income distribution and aggregate demand in the Euro area. Cambridge Journal of Eocnomics: 33 (1): 139-159

Stockhammer, E., Onaran, O. 2004. Accumulation, distribution and employment: a structural VAR approach to a Kaleckian macro-model. Structural Change and Economic Dynamics, 15: 421-47.

Stockhammer, E., Hein, E., Grafl, L. (2010) Globalization and the effects of changes in functional income distribution on aggregate demand in Germany. International Review of Applied Economics, forthcoming

Stockhammer, E, Ederer, S, 2008. Demand effects of a falling wage share in Austria. Empirica: 35, 5: 481-502 


\section{Appendix on Barbosa-Filho and Taylor (2006)}

Barbosa-Filho and Taylor (2006) estimate a similar model for the US economy. They estimate a two equation VAR with a demand equation and a distribution equation (without contemporaneous interaction). The effects for individual components of demand are decomposed from the aggregate results (rather than estimated as behavioural equations). They use quarterly data and use the cyclical component of the HP filter. They find that the US economy is in a profit-led demand regime. Three curious results can be noted. First, the direct distributional effects are very small and get strongly inflated by accelerator effects. Second, the effects of the wage share on demand have alternating signs of comparable absolute order of magnitude at different lags. This may be an indication that the proper specification ought to be in differences. Barbosa-Filho and Taylor do not test this hypothesis. Third, the decomposition gives strong perverse results in the consumption function. Indeed the (negative) effect of an increase in the wage share on consumption is larger than those on investment and net exports combined. This result is at odds with much of the structuralist theory that their work is based on.

As this paper is closely related to our work, we have tried to replicate their results (using the OECD Economic Outlook dataset). While we were able to reproduce their overall results, we also confirmed several severe limitations.

First, Barbosa-Filho and Taylor use the cyclical component of an HP filter. The regression results with these variables suffer from severe autocorrelation problems (no autocorrelation tests are reported by Barbosa-Filho and Taylor). The results are therefore likely to be biased.

Second, the results are very sensitive to the lag length included. While a lag length of two gives the profit-led regime found by Barbosa-Filho and Taylor, a lag length of 4 gives wageled results. Note that in our replication as well as in the original work, the effects of distribution are indeed very small and only get economically significant once they are 
amplified by accelerator effects. A switching of signs of the effect due to a change in lag length is thus less surprising than it may at first appear.

Finally, we also confirm the alternating sign of the effect of the wage share on demand that Barbosa-Filho and Talyor found. An F-test failed to reject the hypothesis that the coefficients (on the coefficient of first and second lags) were identical in absolute value. In other words, a specification in difference form for the wage share is appropriate. In this case, the demand regime is wage led as the first lag has a positive sign and the second lag has a negative sign.

Overall we conclude that the results by Barbosa-Filho and Taylor (2006) suffer from several econometric problems and cannot be regarded as conclusive or robust. 
Tables

Table 1. Estimation results consumption function, $\Delta c_{t}=a_{0}+\sum_{k=1}^{K} a_{Y, k} \Delta y_{t-k}+\sum_{k=1}^{K} a_{W, k} \Delta w_{t-k}+\varepsilon_{t}, 4$ lags

\begin{tabular}{|c|c|c|c|c|c|c|c|c|c|c|c|c|}
\hline & Australia & Canada & Germany & Finland & France & UK & Ireland & Japan & Lux & $\mathrm{NL}$ & Sweden & USA \\
\hline const & 0.007 & 0.005 & 0.005 & 0.003 & 0.005 & 0.005 & 0.003 & 0.004 & 0.004 & 0.002 & 0.002 & 0.007 \\
\hline$t$-value & 5.374 & 4.020 & 3.452 & 2.113 & 3.782 & 3.809 & 1.890 & 2.475 & 4.160 & 1.847 & 1.330 & 7.104 \\
\hline$y(t-1)$ & 0.083 & 0.295 & 0.020 & 0.009 & 0.014 & 0.023 & 0.059 & -0.007 & 0.207 & 0.051 & -0.011 & 0.138 \\
\hline$t$-value & 1.152 & 2.831 & 0.179 & 0.105 & 0.092 & 0.216 & 0.467 & -0.040 & 3.501 & 0.539 & -0.098 & 1.749 \\
\hline$y(t-2)$ & 0.100 & 0.014 & 0.063 & 0.219 & 0.239 & 0.050 & 0.373 & -0.054 & 0.127 & 0.159 & 0.357 & 0.060 \\
\hline$t$-value & 1.473 & 0.133 & 0.581 & 2.789 & 1.463 & 0.473 & 2.823 & -0.305 & 2.080 & 1.737 & 3.175 & 0.765 \\
\hline$y(t-3)$ & -0.002 & 0.139 & 0.009 & 0.307 & 0.032 & 0.262 & -0.052 & 0.522 & 0.044 & 0.332 & 0.030 & 0.060 \\
\hline$t$-value & -0.031 & 1.277 & 0.085 & 3.802 & 0.195 & 2.454 & -0.386 & 2.959 & 0.718 & 3.579 & 0.267 & 0.750 \\
\hline$y(t-4)$ & 0.006 & -0.066 & 0.072 & 0.079 & -0.084 & -0.051 & 0.128 & -0.038 & -0.005 & -0.003 & 0.081 & -0.084 \\
\hline$t$-value & 0.090 & -0.623 & 0.659 & 0.982 & -0.533 & -0.486 & 0.993 & -0.227 & -0.092 & -0.035 & 0.735 & -1.048 \\
\hline$w(t-1)$ & 0.025 & 0.120 & 0.341 & 0.195 & 0.063 & 0.064 & 0.053 & 0.061 & 0.092 & 0.097 & 0.155 & 0.024 \\
\hline$t$-value & 0.460 & 1.173 & 2.913 & 2.429 & 0.480 & 0.709 & 0.555 & 0.401 & 2.797 & 1.218 & 1.868 & 0.275 \\
\hline$w(t-2)$ & 0.120 & -0.014 & 0.106 & -0.092 & 0.000 & -0.204 & -0.039 & -0.074 & 0.066 & 0.102 & 0.113 & -0.052 \\
\hline$t$-value & 2.216 & -0.140 & 0.953 & -1.164 & 0.002 & -2.275 & -0.355 & -0.452 & 1.941 & 1.294 & 1.348 & -0.592 \\
\hline$w(t-3)$ & -0.074 & -0.008 & -0.013 & -0.055 & 0.075 & -0.116 & -0.115 & 0.205 & 0.027 & 0.246 & -0.100 & 0.039 \\
\hline$t$-value & -1.385 & -0.083 & -0.122 & -0.720 & 0.593 & -1.295 & -1.037 & 1.257 & 0.803 & 3.174 & -1.192 & 0.458 \\
\hline$w(t-4)$ & 0.067 & 0.068 & 0.022 & 0.003 & 0.060 & 0.046 & 0.072 & 0.138 & 0.052 & 0.035 & 0.046 & 0.028 \\
\hline t-value & 1.271 & 0.678 & 0.216 & 0.044 & 0.479 & 0.513 & 0.631 & 0.923 & 1.630 & 0.475 & 0.571 & 0.337 \\
\hline DW & 1.963 & 1.973 & 2.364 & 2.118 & 2.316 & 2.039 & 1.466 & 2.339 & 0.742 & 2.392 & 2.038 & 1.668 \\
\hline $\mathrm{R} 2$ & 0.062 & 0.093 & 0.110 & 0.280 & 0.041 & 0.136 & 0.226 & 0.155 & 0.198 & 0.141 & 0.135 & 0.063 \\
\hline sum y & 0.187 & 0.383 & 0.164 & 0.614 & 0.201 & 0.284 & 0.508 & 0.424 & 0.371 & 0.539 & 0.458 & 0.175 \\
\hline sum w & 0.139 & 0.166 & 0.456 & 0.050 & 0.198 & -0.210 & -0.029 & 0.330 & 0.237 & 0.480 & 0.214 & 0.039 \\
\hline sum w (st.s.) & 0.120 & 0.000 & 0.341 & 0.195 & 0.000 & -0.204 & 0.000 & 0.000 & 0.158 & 0.246 & 0.155 & 0.000 \\
\hline
\end{tabular}


Table 2. Summary of effects of a change in the wage share on consumption in specifications with different lag lengths

Table 2.1

all coefficients

\begin{tabular}{|c|c|c|c|c|c|c|c|c|c|}
\hline & 2 lags & 4 lags & 6 lags & 8 lags & & 2 lags & 4 lags & 6 lags & 8 lags \\
\hline Australia & 0.109 & 0.139 & -0.076 & 0.058 & Australia & 0.109 & 0.120 & -0.134 & -0.011 \\
\hline Canada & 0.091 & 0.166 & 0.200 & 0.182 & Canada & 0 & 0 & 0 & 0 \\
\hline Germany & 0.511 & 0.456 & 0.448 & 0.357 & Germany & 0.355 & 0.341 & 0.342 & 0.360 \\
\hline Finland & 0.152 & 0.050 & 0.156 & 0.125 & Finland & 0.226 & 0.195 & 0.221 & 0.157 \\
\hline France & 0.100 & 0.198 & 0.227 & 0.232 & France & 0 & 0 & 0.268 & 0.502 \\
\hline United Kingdom & -0.062 & -0.210 & -0.156 & -0.379 & United Kingdom & 0 & -0.204 & -0.191 & -0.242 \\
\hline Ireland & 0.002 & -0.029 & -0.108 & -0.177 & Ireland & 0 & 0 & 0 & 0 \\
\hline Japan & 0.316 & 0.330 & 0.307 & 0.304 & Japan & 0 & 0 & 0 & 0 \\
\hline Luxembourg & 0.149 & 0.237 & 0.257 & 0.319 & Luxembourg & 0.149 & 0.158 & 0.152 & 0.162 \\
\hline Netherlands & 0.197 & 0.480 & 0.256 & 0.195 & Netherlands & 0 & 0.246 & 0.247 & 0.226 \\
\hline Sweden & 0.293 & 0.214 & 0.131 & 0.188 & Sweden & 0.163 & 0.155 & 0 & U \\
\hline United States & -0.076 & 0.039 & -0.030 & 0.289 & United States & 0 & 0 & 0 & 0 \\
\hline \multirow[t]{2}{*}{ mean } & 0.149 & 0.173 & 0.134 & 0.141 & mean & 0.084 & 0.084 & 0.075 & 0.096 \\
\hline & & & & & no effect & 7 & 5 & 5 & 5 \\
\hline
\end{tabular}

Table 2.2

only coefficients with t-values higher than 1.8
5 
Table 3. Estimation results investment function, $\Delta i_{t}=b_{0}+\sum_{k=1}^{K} b_{Y, k} \Delta y_{t-k}+\sum_{k=1}^{K} b_{W, k} \Delta w_{t-k}+\varepsilon_{t}, 4$ lags

\begin{tabular}{|c|c|c|c|c|c|c|c|c|c|c|c|c|}
\hline & Australia & Canada & Germany & Finland & France & UK & Ireland & Japan & Lux & Netherlands & Sweden & USA \\
\hline const & 0.007 & 0.003 & 0.002 & -0.014 & -0.001 & -0.001 & 0.000 & -0.004 & 0.001 & 0.010 & -0.008 & -0.004 \\
\hline$t$-value & 1.420 & 0.706 & 0.712 & -3.001 & -0.278 & -0.110 & -0.004 & -1.277 & 0.058 & 1.446 & -1.805 & -1.237 \\
\hline$y(t-1)$ & 0.867 & 1.236 & -0.179 & -0.209 & 1.163 & 0.168 & 1.019 & 1.063 & -0.344 & -1.102 & 0.795 & 1.166 \\
\hline$t$-value & 2.980 & 4.124 & -0.633 & -0.715 & 4.229 & 0.352 & 1.806 & 2.933 & -0.552 & -2.133 & 2.494 & 4.653 \\
\hline$y(t-2)$ & -0.167 & -0.478 & 0.271 & 0.785 & 0.212 & 0.634 & -0.363 & 0.089 & 3.551 & 0.347 & 0.943 & 0.324 \\
\hline$t$-value & -0.606 & -1.541 & 0.968 & 2.887 & 0.733 & 1.359 & -0.614 & 0.228 & 5.510 & 0.700 & 2.903 & 1.292 \\
\hline$y(t-3)$ & 0.153 & 0.403 & 0.111 & 0.781 & 0.102 & -0.017 & -0.246 & 0.917 & -1.155 & -0.395 & 0.362 & 0.196 \\
\hline$t$-value & 0.541 & 1.289 & 0.390 & 2.791 & 0.351 & -0.035 & -0.409 & 2.367 & -1.797 & -0.787 & 1.126 & 0.772 \\
\hline$y(t-4)$ & -0.501 & -0.165 & 0.112 & 1.303 & -0.400 & 0.630 & 0.563 & -0.519 & -1.265 & 0.266 & 0.646 & 0.064 \\
\hline$t$-value & -1.736 & -0.544 & 0.398 & 4.655 & -1.432 & 1.363 & 0.975 & -1.408 & -2.101 & 0.509 & 2.021 & 0.250 \\
\hline$w(t-1)$ & -0.122 & -0.143 & -0.252 & 0.258 & 0.392 & -0.114 & 1.236 & 0.323 & 0.249 & 0.456 & 0.372 & 0.144 \\
\hline$t$-value & -0.547 & -0.485 & -0.837 & 0.929 & 1.685 & -0.283 & 2.868 & 0.965 & 0.715 & 1.061 & 1.558 & 0.513 \\
\hline$w(t-2)$ & -0.025 & -0.432 & -0.034 & -0.448 & -0.030 & -0.042 & -1.199 & -0.504 & 1.009 & 0.348 & 0.115 & -0.149 \\
\hline$t$-value & -0.116 & -1.507 & -0.118 & -1.632 & -0.133 & -0.105 & -2.462 & -1.393 & 2.806 & 0.816 & 0.475 & -0.532 \\
\hline$w(t-3)$ & -0.156 & 0.201 & -0.232 & -0.242 & -0.531 & -0.539 & -0.605 & 0.035 & -0.982 & -0.396 & -0.396 & -0.429 \\
\hline$t$-value & -0.721 & 0.693 & -0.849 & -0.905 & -2.374 & -1.352 & -1.218 & 0.096 & -2.733 & -0.941 & -1.639 & -1.582 \\
\hline$w(t-4)$ & -0.227 & 0.230 & -0.340 & 0.319 & -0.201 & 0.257 & 0.180 & -0.549 & 0.737 & 0.015 & 0.245 & 0.034 \\
\hline t-value & -1.059 & 0.798 & -1.305 & 1.202 & -0.900 & 0.651 & 0.354 & -1.670 & 2.197 & 0.036 & 1.053 & 0.131 \\
\hline$d w$ & 1.799 & 1.474 & 2.211 & 2.288 & 1.674 & 2.803 & 1.748 & 2.185 & 2.195 & 2.552 & 2.511 & 1.546 \\
\hline r2 & 0.117 & 0.170 & 0.031 & 0.311 & 0.239 & 0.051 & 0.193 & 0.232 & 0.275 & 0.120 & 0.159 & 0.258 \\
\hline sum y (all) & 0.352 & 0.996 & 0.315 & 2.660 & 1.078 & 1.416 & 0.973 & 1.549 & 0.787 & -0.884 & 2.746 & 1.749 \\
\hline sum w (all) & -0.531 & -0.143 & -0.858 & -0.113 & -0.370 & -0.438 & -0.389 & -0.695 & 1.014 & 0.423 & 0.337 & -0.400 \\
\hline sum ws (st.s.) & 0.000 & 0.000 & 0.000 & 0.000 & -0.531 & 0.000 & 0.037 & 0.000 & 0.765 & 0.000 & 0.000 & 0.000 \\
\hline
\end{tabular}


Table 4 Summary of effects of a change in the wage share on investment in specifications with different lag lengths

Table 4.1

all coefficients

\begin{tabular}{|c|c|c|c|c|c|c|c|c|c|}
\hline & 2 lags & 4lags & 6 lags & 8 lags & & 2 lags & 4lags & 6 lags & 8 lags \\
\hline Australia & -0.239 & -0.531 & -0.976 & -1.128 & Australia & 0 & 0 & 0 & 0 \\
\hline Canada & -0.517 & -0.143 & -0.387 & -1.145 & Canada & 0 & 0 & 0 & ( \\
\hline Germany & -0.064 & -0.858 & -1.257 & -1.181 & Germany & 0 & 0 & 0 & ( \\
\hline Finland & 0.333 & -0.113 & -0.389 & 0.304 & Finland & 0 & 0 & 0 & 0 \\
\hline France & 0.071 & -0.370 & -0.634 & -0.738 & France & 0 & -0.531 & -0.537 & -0.493 \\
\hline United Kingdom & 0.011 & -0.438 & -0.396 & -0.408 & United Kingdom & 0 & 0 & 0 & 0 \\
\hline Ireland & -0.154 & -0.389 & -0.335 & 0.794 & Ireland & -0.154 & 0.037 & 0.378 & 3.506 \\
\hline Japan & -0.167 & -0.695 & -0.493 & -0.420 & Japan & 0 & 0 & 0 & 0 \\
\hline Luxembourg & 0.475 & 1.014 & 0.392 & -0.115 & Luxembourg & 0 & 0.765 & 0.714 & -0.256 \\
\hline Netherlands & 0.798 & 0.423 & -0.333 & -0.410 & Netherlands & 0 & 0 & -0.985 & -0.372 \\
\hline Sweden & 0.719 & 0.337 & -0.486 & -0.152 & Sweden & 0 & 0 & 0 & 0 \\
\hline United States & 0.176 & -0.400 & -0.075 & 1.138 & United States & 0 & 0 & 0 & 0.004 \\
\hline \multirow[t]{2}{*}{ mean } & 0.120 & -0.180 & -0.447 & -0.288 & mean & -0.013 & 0.023 & -0.036 & 0.199 \\
\hline & & & & & no effect & 11 & 9 & 8 & 7 \\
\hline
\end{tabular}


Table 5. Summary of total effects of a change in the wage share on domestic private demand (as \% of GDP) based on difference specifications with different lag lengths

Table 5.1 all effects

Australia
Canada
Germany
Finland
France
United Kingdom
Ireland
Japan
Luxembourg
Netherlands
Sweden
United States
mean
p-led
w-led

$\begin{array}{ccc}2 \text { lags } & \text { 4lags } & 6 \text { lags } \\ 0.058 & -0.097 & -0.914 \\ -0.120 & 0.257 & 0.182 \\ 0.946 & 0.364 & 0.110 \\ 0.526 & 0.020 & 0.034 \\ 0.248 & 0.193 & 0.097 \\ & & \\ -0.113 & -0.585 & -0.465 \\ -0.139 & -0.435 & -0.575 \\ 0.522 & 0.178 & 0.274 \\ 0.758 & 1.450 & 0.904 \\ 0.828 & 1.112 & 0.260 \\ 0.782 & 0.489 & -0.006 \\ -0.080 & -0.091 & -0.093 \\ & & \\ 0.351 & 0.238 & -0.016 \\ 3 & 4 & 5 \\ 9 & 8 & 7\end{array}$

\begin{tabular}{cl}
\multicolumn{3}{c}{ Table 5.2 only sta } & \\
-0.731 & Australia \\
-0.307 & Canada \\
-0.020 & Germany \\
0.454 & Finland \\
0.047 & France \\
& United \\
-0.890 & Kingdom \\
0.321 & Ireland \\
0.318 & Japan \\
0.554 & Luxembourg \\
0.104 & Netherlands \\
0.231 & Sweden \\
1.072 & United States \\
& \\
0.096 & mean \\
4 & p-led \\
8 & w-led
\end{tabular}

2 lags
0.240
0.684
0.438

0.145
0
0.310
0
0.259
0
149
5

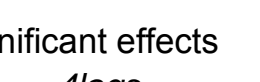

$\begin{array}{lll}2 & 3 & 2 \\ 7 & 5 & 7\end{array}$


Table 6. Summary of total effects of a change in the wage share on domestic private demand according to different (based on short-term effects in ECM specifications with different lag lengths)

Table 5.1 all effects

\begin{tabular}{|c|c|c|c|c|c|}
\hline \multicolumn{5}{|c|}{ Table 5.1 all effects } & \multirow[t]{2}{*}{ Table 5.2 only st } \\
\hline & 2 lags & 4lags & 6 lags & 8 lags & \\
\hline Australia & 0.053 & -0.243 & -1.011 & -0.823 & Australia \\
\hline & - & & & & \\
\hline Canada & 0.077 & 0.334 & 0.285 & -0.193 & Canada \\
\hline Germany & 1.046 & 0.569 & 0.345 & 0.171 & Germany \\
\hline Finland & 0.746 & 0.427 & 0.574 & 1.036 & Finland \\
\hline France & 0.543 & 0.421 & 0.346 & 0.248 & France \\
\hline United Kingdom & 0.012 & -0.354 & -0.176 & -0.617 & United Kingdom \\
\hline Ireland & 0.019 & -0.253 & -0.336 & 0.623 & Ireland \\
\hline Japan & 0.671 & 0.444 & 0.573 & 0.638 & Japan \\
\hline Luxembourg & 0.934 & 1.806 & 1.483 & 1.340 & Luxembourg \\
\hline Netherlands & 1.490 & 2.902 & 2.181 & 1.599 & Netherlands \\
\hline Sweden & 0.893 & 0.769 & 0.422 & 0.669 & Sweden \\
\hline & & & & & \\
\hline United States & 0.012 & 0.034 & 0.039 & 1.237 & United States \\
\hline mean & 0.518 & 0.571 & 0.394 & 0.494 & mean \\
\hline p-led & 3 & 3 & 3 & 3 & p-led \\
\hline w-led & 9 & 9 & 9 & 9 & w-led \\
\hline
\end{tabular}

\begin{tabular}{|c|c|c|c|}
\hline 2 lags & 4lags & 6 lags & 8 lags \\
\hline 0 & 0 & -0.294 & -0.239 \\
\hline 0 & 0 & 0 & 0 \\
\hline 0.653 & 0.647 & 0.652 & 0.690 \\
\hline 0.836 & 0.702 & 0.414 & 0.707 \\
\hline 0.274 & 0.279 & 0.303 & 1.049 \\
\hline 0 & -0.384 & -0.362 & -0.474 \\
\hline 0.027 & 0.199 & 0.512 & 3.469 \\
\hline 0 & 0 & 0 & 0 \\
\hline 0.938 & 1.373 & 1.309 & 1.744 \\
\hline 1.140 & 1.789 & 1.704 & 1.179 \\
\hline 0.689 & 0.456 & 0 & 0 \\
\hline 0 & 0 & 0 & 0.007 \\
\hline 0.380 & 0.424 & 0.353 & 0.678 \\
\hline 0 & 1 & 2 & 2 \\
\hline 7 & 8 & 6 & 6 \\
\hline
\end{tabular}


Table A.1 Granger Causality tests (4 lags, n=145)

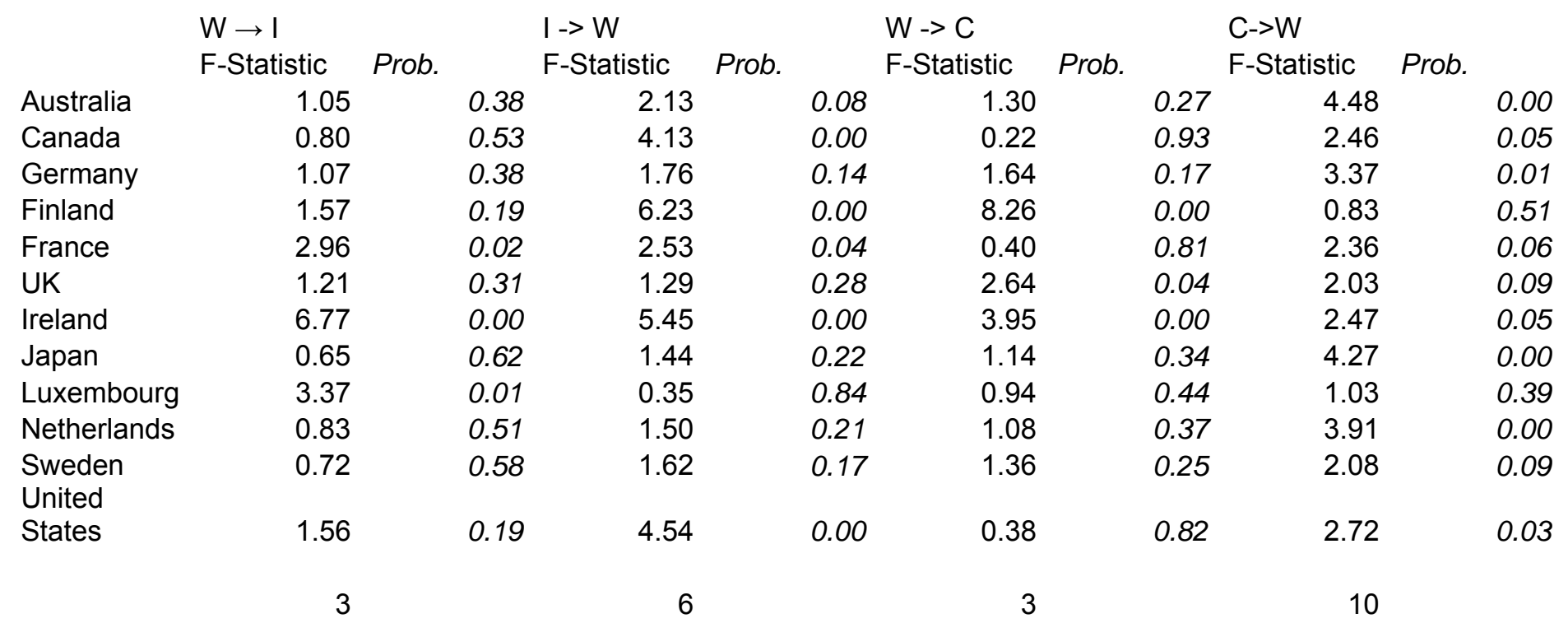


Table A.2 Results of difference specification with testing down procedure

\begin{tabular}{lrrrl} 
& effect cons & effect inv & \multicolumn{1}{c}{ totel eff (weighted) } \\
Australia & 0.056 & 0 & 0.056 Australia \\
Canada & 0 & -0.169 & -0.169 & Canada \\
Germany & 0.373 & 0 & 0.373 Germany \\
Finland & 0.178 & 0 & 0.178 Finland \\
France & 0.240 & -0.172 & 0.067 & France \\
UK & -0.487 & 0 & -0.487 & UK \\
Ireland & 0 & 0.282 & 0.282 & Ireland \\
Japan & 0.220 & -0.130 & 0.089 & Japan \\
Luxembourg & 0.293 & -0.065 & 0.228 Luxembourg \\
Netherlands & 0.027 & -0.138 & -0.111 Netherlands \\
Sweden & -0.121 & -0.123 & -0.244 & Sweden \\
United & & & & \\
States & 0 & -0.014 & -0.014 & United States \\
& & & & \\
& 0.065 & -0.044 & 0.021 & \\
exp sign & 7 & 6 & 7 w-led \\
& 3 & 4 & 5 -led \\
perverse & 2 & 1 & &
\end{tabular}


Table A.3 Long run coefficients of (unrestricted) ECM specification for the consumption function

unrestricted ECM, 8 lags of differences

\begin{tabular}{lrrrrrr} 
& \multicolumn{2}{c}{$\mathrm{c}(\mathrm{t}-1)$} & \multicolumn{2}{c}{$\mathrm{w}(\mathrm{t}-1)$} & & \\
Australia & -0.122 & -2.946 & 0.120 & 2.845 & 0.011 & 0.394 \\
Canada & 0.007 & 0.159 & -0.022 & -0.529 & -0.168 & -3.015 \\
Germany & -0.071 & -1.041 & 0.073 & 0.991 & 0.042 & 0.926 \\
Finland & -0.074 & -1.547 & 0.068 & 1.398 & -0.011 & -0.332 \\
France & -0.046 & -0.844 & 0.040 & 0.763 & -0.009 & -0.349 \\
United Kingdom & -0.064 & -1.118 & 0.069 & 1.035 & -0.076 & -2.105 \\
Ireland & -0.012 & -0.354 & 0.002 & 0.084 & -0.060 & -2.482 \\
Japan & -0.320 & -3.826 & 0.296 & 3.662 & -0.060 & -1.486 \\
Luxembourg & -0.027 & -0.958 & 0.018 & 0.923 & 0.001 & 0.064 \\
Netherlands & -0.097 & -2.131 & 0.088 & 1.921 & 0.044 & 0.861 \\
Sweden & -0.214 & -3.779 & 0.159 & 3.601 & -0.006 & -0.180 \\
United States & 0.141 & 3.159 & -0.155 & -3.195 & -0.156 & -2.616
\end{tabular}

unrestricted ECM, 2 lags of differences

\begin{tabular}{lrrrrrr} 
& $\mathrm{c}(\mathrm{t}-1)$ & \multicolumn{2}{c}{$\mathrm{y}(\mathrm{t}-1)$} & \multicolumn{2}{c}{$\mathrm{w}(\mathrm{t}-1)$} & \\
Australia & -0.101 & -3.125 & 0.101 & 3.068 & 0.016 & 0.665 \\
Canada & 0.003 & 0.068 & -0.014 & -0.317 & -0.106 & -2.446 \\
Germany & -0.067 & -1.104 & 0.064 & 0.993 & 0.010 & 0.288 \\
Finland & -0.097 & -1.719 & 0.088 & 1.565 & -0.031 & -0.975 \\
France & -0.060 & -1.142 & 0.052 & 1.023 & -0.007 & -0.319 \\
United Kingdom & -0.095 & -1.960 & 0.103 & 1.785 & -0.100 & -3.603 \\
Ireland & -0.018 & -0.590 & 0.008 & 0.331 & -0.052 & -2.970 \\
Japan & -0.253 & -3.514 & 0.237 & 3.336 & 0.011 & 0.385 \\
Luxembourg & -0.048 & -2.126 & 0.033 & 2.074 & 0.014 & 0.872 \\
Netherlands & -0.113 & -2.491 & 0.099 & 2.219 & 0.029 & 0.679 \\
Sweden & -0.233 & -4.124 & 0.178 & 3.981 & 0.023 & 0.690 \\
United States & 0.108 & 2.747 & -0.118 & -2.784 & -0.070 & -1.464
\end{tabular}

Note: critical values for ECM cointegration are $-3.2,-3.6$ and -4.2 at the $10 \%, 5 \%$ and $1 \%$ level respectively (for T= 100, $\mathrm{k}=2$; Banjeree eta 1998 ) 
Table A.4 Long run coefficients of (unrestricted) ECM specification for the investment function unrestricted ECM, 8 lags of differences

\begin{tabular}{lllllrr} 
& $\mathrm{i}(\mathrm{t}-1)$ & \multicolumn{2}{c}{$\mathrm{w}(\mathrm{t}-1)$} & & \\
Australia & -0.046 & -1.325 & 0.078 & 1.740 & 0.087 & 0.838 \\
Canada & -0.041 & -1.273 & 0.012 & 0.290 & -0.437 & -2.774 \\
Germany & -0.099 & -1.918 & 0.099 & 1.684 & -0.030 & -0.288 \\
Finland & -0.096 & -2.807 & 0.076 & 2.227 & 0.087 & 0.738 \\
France & -0.014 & -0.509 & 0.016 & 0.590 & -0.062 & -1.458 \\
United Kingdom & -0.396 & -5.289 & 0.551 & 5.077 & 0.008 & 0.056 \\
Ireland & -0.059 & -2.110 & 0.060 & 1.847 & 0.008 & 0.082 \\
Japan & -0.056 & -1.249 & 0.048 & 0.809 & -0.133 & -1.440 \\
Luxembourg & -0.178 & -3.416 & 0.190 & 3.405 & -0.049 & -0.476 \\
Netherlands & -0.344 & -4.028 & 0.290 & 3.052 & -0.344 & -1.961 \\
Sweden & -0.099 & -2.722 & 0.098 & 2.468 & -0.008 & -0.092 \\
United States & -0.007 & -0.229 & 0.000 & -0.007 & -0.453 & -2.447
\end{tabular}

unrestricted ECM, 2 lags of differences

\begin{tabular}{lllllll} 
& $\mathrm{i}(\mathrm{t}-1)$ & \multicolumn{3}{c}{$\mathrm{w}(\mathrm{t}-1)$} & \\
Australia & -0.049 & -1.460 & 0.066 & 1.594 & -0.034 & -0.384 \\
Canada & -0.029 & -0.964 & 0.007 & 0.192 & -0.335 & -3.031 \\
Germany & -0.105 & -2.620 & 0.094 & 2.358 & -0.123 & -1.461 \\
Finland & -0.056 & -1.955 & 0.025 & 0.956 & -0.139 & -1.473 \\
France & -0.040 & -2.048 & 0.041 & 2.237 & -0.076 & -2.157 \\
United Kingdom & -0.324 & -5.108 & 0.444 & 4.860 & -0.046 & -0.409 \\
Ireland & -0.052 & -1.768 & 0.043 & 1.373 & -0.057 & -0.713 \\
Japan & -0.081 & -2.755 & 0.094 & 2.829 & -0.018 & -0.293 \\
Luxembourg & -0.208 & -4.016 & 0.216 & 3.944 & -0.085 & -0.973 \\
Netherlands & -0.248 & -4.211 & 0.193 & 3.070 & -0.323 & -2.173 \\
Sweden & -0.081 & -2.604 & 0.075 & 2.106 & -0.093 & -1.144 \\
United States & -0.040 & -1.453 & 0.042 & 1.110 & -0.262 & -1.606
\end{tabular}

Note: critical values for ECM cointegration are $-3.2,-3.6$ and -4.2 at the $10 \%, 5 \%$ and $1 \%$ level respectively (for T= 100, $\mathrm{k}=2$; Banjeree eta 1998 ) 